Revised manuscript

Final version published:

Eur. J. Med. Chemistry, 115: 361-368 (2016)

doi: 10.1016/j.ejmech .2016.03.034. 


\title{
Cell-penetrating conjugates of pentaglutamylated methotrexate as potential anticancer drugs against resistant tumor cells
}

\author{
Ildikó Szabó $^{1}$, Erika Orbán ${ }^{1}$, Gitta Schlosser ${ }^{1}$, Ferenc Hudecz $^{1,2}$, Zoltán Bánóczi $^{1,2 *}$ \\ ${ }^{1}$ MTA-ELTE Research Group of Peptide Chemistry, Budapest, Hungary \\ ${ }^{2}$ Department of Organic Chemistry, Eötvös L. University, Budapest, Hungary
}

AUTHOR EMAIL ADDRESS banoczi@elte.hu

CORRESPONDING AUTHOR FOOTNOTE: Research Group of Peptide Chemistry,

Hungarian Academy of Sciences, Eötvös L. University, Budapest, Pázmány P. Sétány 1/A, H1117, Hungary. Tel.: +361 372-2500/1414; fax: +361372 2620. E-mail address:

banoczi@elte.hu (Z.Bánóczi). 


\begin{abstract}
The emerging resistance of tumor cells against methotrexate (MTX) is one of the major limitations of the MTX treatment of tumorous diseases. The disturbance in the polyglutamation which is a main step in the mechanism of methotrexate action is often the reason of the resistance. Delivery of polyglutamylated MTX into cells may evade the mechanisms that are responsible for drug resistance. In this study conjugates of methotrexate and its pentaglutamylated derivatives with cell-penetrating peptides - penetratin and octaarginine - were investigated. The cellular-uptake and in vitro cytostatic activity of conjugates were examined on breast cancer cell cultures (MDA-MB-231 as resistant and MCF-7 as sensitive cell culture). These cell cultures showed very different behaviour towards the conjugates. Although the presence of pentaglutamyl moiety significantly decreased the internalisation of conjugates, some of them were significantly active in vitro. All of the conjugates were able to penetrate in some extent into both cell types, but only the conjugates of penetratin showed in vitro cytostatic activity. The most effective conjugates were the MTX-Glu 5 -Penetratin(desMet) and MTX-Glu 5 -GFLG-Penetratin(desMet). The latter was effective on both cell cultures while the former was active only on the resistant tumor cells. Our results suggest that the translocation of polyglutamylated MTX may be a new way to treat sensitive and more importantly resistant tumors. While both penetratin and octaarginine peptides were successfully used to deliver several kinds of cargos earlier in our case the activity of penetratin conjugates was more pronounced.
\end{abstract}

Key words: methotrexate, pentaglutamylated methotrexate, penetratin, oligoarginine, drug resistance, cell-penetrating peptide 


\section{Introduction}

Methotrexate (4-amino-10-methylfolic acid, MTX) was the first antimetabolite used in the treatment of tumorous diseases from the 1950s. As an effective anticancer drug it is clinically used to treat childhood acute lymphoblastic leukemia and a number of other hematologic malignancies [1]. Methotrexate, belonging to the antifolate antimetabolite family, can be internalised into cells by specific transporters - the membrane-bound reduced folate carrier (RFC-1) and/or folate-binding proteins (folate receptors Fro, FR $\beta$ and FR $\gamma$ ) [2]. Inside the cell sequential addition of Glu moiety/moieties occurs by the enzyme folylpolyglutamate synthetase (FPGS) [3-5]. Polyglutamylated MTX exhibiting higher affinity to folatemetabolizing enzymes play crucial role in the metabolism of folic acid and disturb the biosynthesis of thymidine and purine, inhibit the synthesis of DNA and could lead to cell death.

During the polyglutamation 5-8 glutamic acid residues are coupled to the MTX via amide linkage forming $\gamma$-peptide bonds. The MTX is a poor substrate of the FPGS which catalyses the glutamic acid attachment and its binding competes with intracellular folates [6]. The polyglutamylated forms of MTX can inhibit the dihydrofolate reductase and timidylate synthase enzymes. The presence of the polyglutamyl moiety essentially prevents the efflux of MTX from the cell because derivatives containing more than three glutamic acid residues are not substrates of multidrug resistance protein (MRP 3) [7] and of the folate transporter systems [8]. Thus the polyglutamation is a very important process in the action of MTX. The concentration of polyglutamylated MTX in the cytosol is modulated by the activity of FPGS and of the enzyme $\gamma$-glutamyl hydrolase $(\mathrm{GGH})$, catalysing the removal of Glu residues $[9,10]$. Therefore, the presence of polyglutamylated MTX derivatives depends on the balance of glutamic acid attachment and removal.

Although several second and third generation antifolates have been developed for clinical use, the main drawback is the development of the evolving drug resistance. There are various processes which are responsible for the drug resistance: i) decreased cellular uptake caused by the malfunction of folate transporters [11]; ii) increased efflux related to the overexpression of multidrug resistance transporters [12]; and/or iii) decreased level of polyglutamation due to inactivation or decreased activation of respective enzymes that take part in these processes [13]. The drug resistance can be intrinsic or acquired. Some studies showed that the defect in the polyglutamation can result in the intrinsic drug resistance [14,15]. Therefore the intracellular delivery of polyglutamylated MTX may provide an effective antitumor drug against resistant tumor cells as well.

Polyglutamylated MTX derivatives are very hydrophilic, and they are not substrates of folate transporter systems (RFC-1 and/or FRs) delivering folates into the cells. Consequently, these compounds are not able to enter through the cell membrane. This disadvantage may be overcome by using cell-penetrating peptides (CPPs). CPPs are short oligopeptides (natural and/or of synthetic origin) with cell internalisation capability. Among the first peptides discovered, derivatives from proteins: HIV-1 Tat [16,17] and Antennapedia protein of Drosophila could be mentioned [18]. These oligopeptides are able to penetrate across the cell membrane even in the presence of various, covalently attached cargos (e.g. peptides, peptidenucleic acids, oligonucleotides) [19]. 
For targeted delivery into sensitive and/or resistant tumor cells MTX or pemetrexed [20] has been conjugated to protein [21], peptides including CPP [22-25], polymeric polypeptides [26], dendrimers [27,28] and oligosaccharides [29].

In spite of the potency of polyglutamylated MTX as effective drug against resistant tumors only few studies were reported on conjugates with this molecule. An early paper described conjugates in which MTX with different length of polyglutamyl chains were attached to polymeric polylysine (average $M=27000$ and 52000) [30]. In these conjugates the polyglutamylated MTX was coupled via amide bond between the $\alpha / \gamma$-carboxylic group of glutamic acids and $\varepsilon$-amino group of lysine side chains. Since the unprotected form was used in the conjugation reaction the exact structure of the conjugates (the carboxylic group involved in the formation of the amide bond) is unknown. The number of MTX attached to the polymer was between 2 and 11. The conjugates showed inhibitory activity of sensitive (H35) and MTX transport resistant (H35R) strains of hepatoma cells. In a recent study the polyglutamylated forms of MTX were conjugated with sequence-defined oligo(ethanamino)amide [31]. These compounds and the free MTX exhibited similar activity against human cervix carcinoma KB cells in vitro.

Based on our promising results on cell penetrating peptide - antitumor drug (daunomycin, vinblastine [32,33]) or enzyme activator/substrate peptide [34,35] conjugates our aim was to study the cell-penetrating peptide concept to deliver pentaglutamylated methotrexate into tumor cells. Here we describe the synthesis and characterization of a novel set of conjugates in which pentaglutamylated MTX is covalently attached to the $N$-terminal of cell-penetrating peptides via peptide bond. Two conjugate families are reported here with two different types of CPPs (octaarginine or modified penetratin) possessing different mechanisms of uptake. The cytostatic effect as well as cellular uptake properties of conjugates were studied on sensitive and resistant breast tumor cell lines in vitro. Data collected were comparatively analysed with those obtained with MTX-conjugates without pentaglutamyl moiety as well. We observed that the presence of penetratin(desMet) highly influenced the activity of pentaglutamylated MTX on resistant breast cancer cells even in comparison with the MTX-conjugate, but not on MCF7 cells. Interestingly, no in vitro cytotoxic effect was documented with conjugate containing $\mathrm{Arg}_{8}$ as CPP. Our results show that the insertion of an enzyme labile spacer (GFLG) between pentaglutamylated MTX and penetratin(desMet) could maintain (MDA-MB-231) or increase (MCF-7 cell) the activity of the conjugate as well.

\section{Materials and Methods}

All amino acid derivatives, $N, N^{\prime}$-diisopropylcarbodiimide (DIC) and Rink-amide MBHA resin were purchased from IRIS Biotech GmbH (Marktredwitz, Germany). N,Ndiisopropylethylamine (DIEA), 1.8-diazabicyclo[5.4.0]undec-7-ene (DBU), thioanisole, 1,2ethandithiol (EDT) were FLUKA (Buchs, Switzerland), while 1-hydroxybenzotriazole (HOBt), trifluoroacetic acid (TFA) and phenol were Sigma Aldrich (Budapest, Hungary) products. Solvents for synthesis and purification were obtained from Molar Chemicals Ltd (Budapest, Hungary). Carboxyfluorescein (cf) and all other chemicals used in biological experiments were purchased from Sigma Aldrich (Hungary). Buffers were prepared with distilled water. 


\section{Synthesis of peptides and peptide-conjugates}

The conjugates were built up by solid-phase peptide synthesis on Rink amide MBHA resin using $\mathrm{Fmoc} /{ }^{t} \mathrm{Bu}$ strategy. The side chain of amino acids were protected by 2,2,4,6,7pentamethyldihydrobenzofuran-5-sulfonyl group (Pbf, in Arg), by trityl (Trt, in Asn, Gln), by tert-butyl group $\left({ }^{t} \mathrm{Bu}\right.$, in Glu) and by tert-butyloxycarbonyl group (Boc, in Lys). The $\mathrm{N}$ terminal Fmoc protecting group was removed with $2 \%$ piperidine in the presence of $2 \% 1.8$ diazabicyclo[5.4.0] undec-7-ene (DBU) in DMF $(2+2+5+10 \mathrm{~min})$. This reagent was removed by washing with DMF ( $8 \times 0.5 \mathrm{~min})$. In the coupling reaction, amino acid derivatives, which were used in 3 molar excess to the resin capacity, were activated by $N, N^{\prime}$ diisopropylcarbodiimide (DIC) and 1-hydroxybenzotriazole (HOBt) dissolved in DMF. The reaction proceeded at $\mathrm{RT}$ for $60 \mathrm{~min}$. Then, the resin was washed with DMF $(2 \times 0.5 \mathrm{~min})$ and dichloromethane (DCM) $(3 \times 0.5 \mathrm{~min})$. Ninhydrin assay was used to monitor the efficiency of the coupling reaction [36]. After the removal of the terminal $N^{\alpha}$-Fmoc group, methotrexate (MTX) or 5(6)-carboxyfluorescein (cf) were attached to the peptide using the HOBt-DIC coupling reagents. The free compounds were obtained by cleavage from the resin with $10 \mathrm{~mL}$ TFA containing $0.75 \mathrm{~g}$ phenol, $0.5 \mathrm{~mL}$ distilled water, $0.5 \mathrm{~mL}$ thioanisole and $0.25 \mathrm{~mL} \mathrm{1,2-}$ ethandithiol (EDT) as scavengers. Crude products were precipitated by dry diethyl-ether, dissolved in $10 \%$ acetic acid and freeze-dried. The crude peptide was purified by RP-HPLC as described below. The purified compounds were characterized by analytical RP-HPLC and ESI-MS (Table 1). The purity of the compounds was higher than $95 \%$.

\section{RP-HPLC}

Analytical RP-HPLC was performed on a Knauer (Herbert Knauer GmbH, Berlin, Germany) HPLC system using a Phenomenex Jupiter C18 column (250x4.6mm I.D.) with $5 \mu \mathrm{m}$ silica (300 ̊ pore size) (Torrance, CA USA) as a stationary phase. Linear gradient elution ( 0 min $0 \% \mathrm{~B} ; 5$ min $0 \% \mathrm{~B} ; 50 \mathrm{~min} 90 \% \mathrm{~B})$ with eluent $\mathrm{A}(0.1 \%$ TFA in water) and eluent $\mathrm{B}(0.1 \%$ TFA in acetonitrile-water $(80: 20, \mathrm{~V} / \mathrm{V}))$ was used at a flow rate of $1 \mathrm{~mL} / \mathrm{min}$ at ambient temperature. Peaks were detected at $\lambda=220 \mathrm{~nm}$. The samples were dissolved in eluent B. In the other cases Exformma (Exformma Technology (ASIA) Co., Ltd, Hong Kong, China) HPLC system was used. The column was Agilent Zorbax SB-C18 4.6mmx150mm, $100 \AA$. The applied linear gradient elution was $0 \min 0 \% \mathrm{~B}, 2 \min 0 \% \mathrm{~B}, 22 \min 90 \% \mathrm{~B}$ with 1 $\mathrm{mL} / \mathrm{min}$ flow rate. The detection was carried on at $\lambda=220 \mathrm{~nm}$.

The crude products were purified on a semi-preparative Phenomenex Jupiter C18 column (250x10mm I.D.) with $10 \mu \mathrm{m}$ silica (300 A pore size) (Torrance, CA, USA). Flow rate was 4 $\mathrm{mL} / \mathrm{min}$. Linear gradient elution was applied. The samples for purification were dissolved in eluent A containing few percent eluent B.

\section{Mass Spectrometry}


The molecular mass of peptides as well as conjugates was determined by ESI-MS. Electrospray ionization mass spectrometric analysis was performed on a Bruker Daltonics Esquire 3000 plus (Germany) ion trap mass spectrometer. The samples were dissolved in acetonitrile-water (50:50, V/V), containing $0.1 \%$ acetic acid. Samples were analyzed by direct injection using a syringe pump. Instrumental parameters were the following: capillary voltage: $4 \mathrm{kV}$, nebulizer gas: 10 psi, dry gas: $4 \mathrm{~L} / \mathrm{min}$, heated capillary temperature: $250{ }^{\circ} \mathrm{C}$.

\section{Cell cultures for in vitro studies}

MCF-7 (ATCC: HTB-22) human breast adenocarcinoma [37] and MDA-MB-231 (ATCC: HTB-26) human triple negative breast adenocarcinoma [38] cells were used for the analysis of the in vitro cytostatic effect of MTX containing conjugates and controls (MTX, $\operatorname{Arg}_{8}$ and penetratin) and also for the investigation of the cellular uptake of carboxyfluorescein labelled compounds. MCF-7 cells were maintained in DMEM supplemented with $10 \%$ heatinactivated fetal calf serum (FCS), non-essential amino acids (NEAA), pyruvate $(1 \mathrm{mM}), \mathrm{L}-$ Gln $(2 \mathrm{mM})$ and gentamicin $(160 \mu \mathrm{g} / \mathrm{mL})$. MDA-MB-231 cells were cultured in RPMI-1640 supplemented with 10\% FCS, L-Gln $(2 \mathrm{mM})$ and gentamicin $(16 \mu \mathrm{g} / \mathrm{mL})$. Cells were maintained in plastic tissue culture dishes at $37^{\circ} \mathrm{C}$ with a humidified atmosphere containing $5 \% \mathrm{CO}_{2} / 95 \%$ air.

\section{Determination of the in vitro cellular uptake profile by flow cytometry}

MCF-7 and MDA-MB-231 cells were cultured as described above. In order to study the cellular uptake of fluorescently labelled compounds, $10^{5}$ cells per well were plated on 24-well plates. After $24 \mathrm{~h}$ incubation at $37^{\circ} \mathrm{C}$, cells were treated with the compounds in serum-free medium for $90 \mathrm{~min}$. The cellular uptake was analysed at 1,5 and $10 \mu \mathrm{M}$ concentrations. Cells treated with serum-free medium for $90 \mathrm{~min}$ were used as negative control. After incubation, the solutions of conjugates were removed from the cells and the cells were treated with 100 $\mu \mathrm{L}$ trypsin for $10 \mathrm{~min}$. The activity of trypsin was terminated by the addition of $900 \mu \mathrm{L}$ HPMI (glucose, $\mathrm{NaHCO}_{3}, \mathrm{NaCl}, \mathrm{HEPES}, \mathrm{KCl}, \mathrm{MgCl}_{2}, \mathrm{CaCl}_{2}, \mathrm{Na}_{2} \mathrm{HPO}_{4} \cdot 2 \mathrm{H}_{2} \mathrm{O}$ ) containing $10 \%$ fetal calf serum, and the cells were moved from the plate to FACS-tubes. Cells were centrifuged at $216 \mathrm{~g}$ at $4^{\circ} \mathrm{C}$ for $5 \mathrm{~min}$ and the supernatant was removed. Cells were re-suspended in $500 \mu \mathrm{L}$ HPMI. The fluorescence intensity of cells was monitored by flow cytometry (BD LSR II, BD Bioscience, San Jose, CA). Data were analyzed with FACSDiVa 5.0 software.

\section{Analysis of the in vitro cytostatic activity of the conjugates}

The cells were grown to confluency and were plated into 96-well plate with initial cell number of $5 \cdot 10^{3}$ per well. After $24 \mathrm{~h}$ incubation at $37{ }^{\circ} \mathrm{C}$, cells were treated with the compounds at $1.28 \cdot 10^{-3}-100 \mu \mathrm{M}$ concentration range for $3 \mathrm{~h}$ in $200 \mu \mathrm{L}$ final volume. Control cells were treated with serum free medium at $37{ }^{\circ} \mathrm{C}$ for $3 \mathrm{~h}$. After incubation the cells were washed twice with serum free medium. For the analysis of the in vitro cytostatic effect, cells 
were cultured for an additional $72 \mathrm{~h}$ in serum containing medium. On day 4, MTT assay $[39,40]$ was carried out in order to determine the $\mathrm{IC}_{50}$ values of the compounds. Briefly, $45 \mu \mathrm{L}$ of MTT solution was added to each well $(2 \mathrm{mg} / \mathrm{mL}$, dissolved in serum-free medium). Following the $4 \mathrm{~h}$ incubation, plates were centrifuged at $900 \mathrm{~g}$ for $5 \mathrm{~min}$, and the supernatant was removed. The precipitated purple crystals were dissolved in $100 \mu \mathrm{L}$ DMSO and the absorbance was determined at $\lambda=540 \mathrm{~nm}$ and $620 \mathrm{~nm}$ using ELISA plate reader (iEMS Reader, Labsystems, Finland). The percent of cytostasis was calculated using the following equation: Cytostatic effect $(\%)=\left[1-\left(\mathrm{OD}_{\text {treated }} / \mathrm{OD}_{\text {control }}\right)\right] \mathrm{x} 100$; where $\mathrm{OD}_{\text {treated }}$ and $\mathrm{OD}_{\text {control }}$ correspond to the optical densities of the treated and the untreated control cells, respectively. In each case three independent experiments were carried out with 4 parallel measurements. The $50 \%$ inhibitory concentration $\left(\mathrm{IC}_{50}\right)$ values were determined from the dose-response curves. The curves were defined using MicrocalTM Origin (version 9.2) software: cytostasis was plotted as a function of concentration, fitted to a sigmoidal curve, and based on this curve, the $\mathrm{IC}_{50}$ value was determined. $\mathrm{IC}_{50}$ represents the concentration of a compound required for $50 \%$ inhibition in vitro and expressed as micromolar units.

\section{Results}

After the internalisation MTX typically undergoes polyglutamation [3-5]. These derivatives (MTX- $(\mathrm{Glu})_{\mathrm{n}}$ where $\mathrm{n}=5$ to 8 ) are very important to maintain the effective intracellular concentration. Alteration of the homeostasis of the polyglutamylated MTX forms often results in the development of drug resistance [13]. For this study we have selected the pentaglutamylated derivative $\left(\mathrm{MTX}-\mathrm{Glu}_{5}\right)$ considering that this compound is not a substrate of folate transport systems. We have examined the effect of the pentaglutamylated derivative $\left(\mathrm{MTX}-\mathrm{Glu}_{5}\right)$ on the cell viability as well as on the uptake properties of two different tumor cell cultures. For intracellular delivery its conjugates with cell-penetrating peptides were also synthesised, since - due to its negative charges - this methotrexate derivative is not able to penetrate across the cell-membrane.

\section{Synthesis of the conjugates}

The different cell-penetrating peptides could have very diverse internalisation mechanisms and thus have high influence on the intracellular fate of the covalently attached cargo moiety. Although both octaarginine and penetratin are positively charged with several arginine residues in the sequence, based on the characteristics of their internalisation, the two peptides belong to different classes of cell-penetrating peptides [41]; penetratin is secondary amphipathic [42], while octaarginine is non-amphipathic cell-penetrating peptide [43]. For studying whether the difference between the two CPP's has any effect on in vitro cytostatic activity, MTX-conjugates of both peptides were prepared. Since methionine in the penetratin sequence could be oxidized under various conditions and might decrease the stability of conjugates, penetratin derivative without methionine (RQIKIWFQNRRKWKK (Penetratin(desMet))) was produced. Earlier studies [44] as well as our own experience (data 
is not shown) proved that this Met residue can be removed from the sequence without decreasing the internalisation ability.

During the intracellular attachment of polyglutamyl chain $\gamma$-peptide bond formed between the glutamic acids. However, the cell has also an apparatus to remove this chain from MTX $[9,10]$. Therefore to avoid the decomposition of our MTX derivative by gamma-glutamyl hydrolase, the glutamic acid residues were connected with their $\alpha$-carboxyl group.

The conjugates of MTX and MTX-Glu (Figure 1) with cell-penetrating peptide were synthesised by solid phase peptide synthesis using standard Fmoc/t Bu strategy.

A)<smiles>CC(C)C(=O)CCC(NC(=O)c1ccc(N(C)Cc2cnc3nc(N)nc(N)c3n2)cc1)C(=O)O</smiles>

B)<smiles>CC(C)C(=O)C(CCC(=O)O)NC(=O)CCC(NC(=O)c1ccc(N(C)Cc2cnc3nc(N)nc(N)c3n2)cc1)C(=O)O</smiles>

Figure 1 The structure of MTX (A) and MTX-Glu $(B)$ containing CPP-conjugates

First the cell-penetrating peptides with or without pentaglutamyl moiety at their $N$-terminus were built up and MTX was attached to the free $N$-terminal amino group of peptides using DIC and HOBt coupling reagents. Then the conjugates were cleaved from the resin by TFA cleavage mixture and were purified by RP-HPLC as described in the Experimental section. The characterisation of conjugates was performed by analytical RP-HPLC and ESI-MS (Table 1). During the purification only one peak was isolated with the correct molecular mass. As the MTX contains two carboxyl groups and none of them was protected, the formation of two main isomers could be expected during the synthesis of MTX-conjugates. Besides this the racemisation of glutamic acid residue in the MTX molecule may also occur, the D-isomers might be also present in the mixture. Based on earlier results using the same coupling strategy but different peptide component, MTX mainly coupled via its $\gamma$-carboxyl group in these circumstances [22]. Thus we could isolate the mixture of isomer conjugates containing mainly $\gamma$-peptide bond between the MTX and the peptides. For the cellular uptake studies fluorescence labelled conjugates were also prepared. These derivatives were synthesised as MTX conjugates, but cf was attached instead of MTX.

Since we know little about the fate of internalised conjugates, and about the potential release of MTX and MTX-Glu 5 , we have prepared conjugates with a tetrapeptide spacer (GFLG) cleavable by a lysosomal enzyme cathepsin B inserted between the cell-penetrating peptide and drug component. The cytostatic as well as uptake properties of these compounds were also studied. 
Table 1. Chemical characteristics of peptides and peptide-conjugates

\begin{tabular}{|c|c|c|c|}
\hline \multirow{2}{*}{ Compounds } & \multirow[t]{2}{*}{$\mathrm{R}_{\mathrm{t}}(\min )$} & \multicolumn{2}{|c|}{$\mathrm{ESI}^{\mathrm{M}} \mathrm{MS}^{\mathrm{c}}$} \\
\hline & & $\mathrm{M}_{\text {cal. }}$ & $\mathrm{M}_{\text {meas. }}$ \\
\hline $\operatorname{Arg}_{8} *$ & $10.3^{\mathrm{b}}$ & 1266.5 & 1266.3 \\
\hline Penetratin* & $12.9^{\mathrm{b}}$ & 2245.7 & 2246.2 \\
\hline $\mathrm{Mtx}-\mathrm{Arg}_{8}$ & $21.2^{\mathrm{a}}$ & 1702.6 & 1703.7 \\
\hline Mtx-Penetratin(desMet)* & $24.5^{\mathrm{a}}$ & 2251.0 & 2251.4 \\
\hline Mtx-Glu $-\mathrm{Arg}_{8}$ & $21.9^{\mathrm{a}}$ & 2348.5 & 2349.0 \\
\hline Mtx-Glus-Penetratin(desMet) & $25.3^{\mathrm{a}}$ & 3196.6 & 3197.1 \\
\hline Mtx-GFLG-Arg & $12.6^{\mathrm{b}}$ & 2077.4 & 2077.8 \\
\hline Mtx-GFLG-Penetratin(desMet) & $14.1^{\mathrm{b}}$ & 2925.4 & 2925.9 \\
\hline 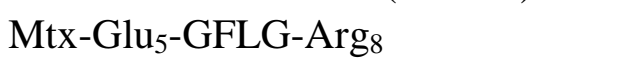 & $12.4^{\mathrm{b}}$ & 2722.9 & 2723.3 \\
\hline Mtx-Glu - -GFLG-Penetratin(desMet) & $14.1^{\mathrm{b}}$ & 3571.0 & 3570.9 \\
\hline $\mathrm{cf}-\mathrm{Arg}_{8}$ & $11.6^{\mathrm{b}}$ & 1624.8 & 1625.4 \\
\hline cf-Penetratin(desMet) & $14.1^{\mathrm{b}}$ & 2472.9 & 2473.2 \\
\hline $\mathrm{cf}-\mathrm{Glu}_{5}-\mathrm{Arg}_{8}$ & $22.9^{\mathrm{a}}$ & 2270.4 & 2270.7 \\
\hline cf-Glu 5 -Penetratin(desMet) & $27.8^{\mathrm{a}}$ & 3118.4 & 3119.4 \\
\hline cf-GFLG-Penetratin(desMet) & $15.9^{\mathrm{b}}$ & 2847.3 & 2846.9 \\
\hline cf-Glu - -GFLG-Penetratin(desMet) & $15.0^{\mathrm{b}}$ & 3492.9 & 3492.8 \\
\hline
\end{tabular}

* Penetratin: RQIKIWFQNRRMKWKK, Arg: RRRRRRRR, Penetratin(desMet): RQIKIWFQNRRKWKK The purity of the compounds was higher than $95 \%$.

${ }^{a}$ RP-HPLC retention time value. Column: Phenomenex Luna C18(2) $5 \mu \mathrm{M}, 250 \times 4.6 \mathrm{~mm}, 100 \AA \AA$. Linear gradient elution: 0 min $0 \%$ B; 5 min $0 \%$ B; 50 min $90 \%$ B with eluent A (0.1\% TFA in water) and eluent B (0.1\% TFA in acetonitrile-water $(80: 20, \mathrm{~V} / \mathrm{V}))$ were used at a flow rate of $1 \mathrm{~mL} / \mathrm{min}$ at ambient temperature. Peaks were detected at $\lambda=220 \mathrm{~nm}$.

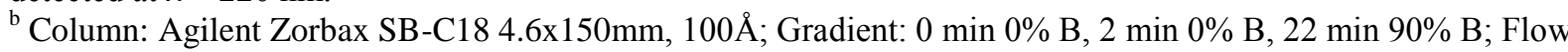
rate: $1 \mathrm{~mL} / \mathrm{min}$; $\mathrm{RT}, \lambda=220 \mathrm{~nm}$.

${ }^{c}$ ESI-MS analysis was carried out on a Bruker Esquire 3000 plus equipment (Germany). The sample was dissolved in acetonitrile-water $(50: 50, \mathrm{~V} / \mathrm{V}), 0.1 \%$ acetic acid.

\section{In vitro cytostatic effect of the conjugates}

The in vitro cytostatic activity of MTX-conjugates was examined on two tumor cell lines, MCF-7 human breast adenocarcinoma and MDA-MB-231 human triple negative breast adenocarcinoma cell lines (Table 2). The main difference between these two cell cultures is their receptor status. MCF-7 cells express oestrogen and progesterone receptors, but MDAMB-231 cells are oestrogen, progesterone and HER2 receptor negative (called triple negative) cells [45]. This different receptor status could cause significant differences in the therapeutic responses to various drugs, like in case of MTX. Considering that MCF-7 cells are sensitive to MTX treatment, while MDA-MB-231 cells are MTX resistant, these two cell cultures were selected as models for our in vitro experiments. It is important to note that the drug resistance of MDA-MB-231 cells is due to the lack of reduced folate carrier [46].

On MCF-7 cells the free MTX was highly active with $\mathrm{IC}_{50}=0.8 \mu \mathrm{M}$, while the free cellpenetrating peptides, as expected exhibited no activity in the concentration range studied here $\left(\mathrm{IC}_{50}>100 \mu \mathrm{M}\right)$. Among the two MTX conjugates only the MTX-Penetratin(desMet) showed some moderate activity $\left(\mathrm{IC}_{50}=40.2 \mu \mathrm{M}\right.$ ), while the octaarginine conjugate was completely inefficient. The conjugates of MTX-Glu 5 were fully inactive. The influence of enzyme labile 
spacer (GFLG) was also studied. The presence of the GFLG tetrapeptide spacer both in the $\mathrm{Arg}_{8}$ and penetratin(desMet) conjugates of MTX increased the activity $\left(\mathrm{IC}_{50}=31.3 \mu \mathrm{M}\right.$ for MTX-GFLG-Arg ${ }_{8}$ and $\mathrm{IC}_{50}=13.9 \mu \mathrm{M}$ for MTX-GFLG-Penetratin(desMet)). In case of MTX-Glu ${ }_{5}$ conjugates the presence of the spacer resulted in higher activity only in case of MTX-Glu 5 -GFLG-Penetratin(desMet) $\left(\mathrm{IC}_{50}=0.3 \mu \mathrm{M}\right)$, while the octaarginine conjugate was ineffective.

Table 2 In vitro cytostatic activity of MTX-conjugates on tumor cells

\begin{tabular}{|lcc|}
\hline \multicolumn{1}{|c}{ Compound } & \multicolumn{2}{c|}{$\mathrm{IC}_{50}(\mathrm{sd})(\mu \mathrm{M})^{\mathrm{a}}$} \\
Mtx & $>100$ & $0.8(0.3)$ \\
Arg $_{8}$ & $>100$ & $>100$ \\
Penetratin & $>100$ & $>100$ \\
Mtx-Arg $_{8}$ & $\sim 100$ & $>100$ \\
Mtx-Penetratin(desMet) & $12.9(4.0)$ & $40.2(14.4)$ \\
Mtx-Glu $_{5}$-Arg & $>100$ & $>100$ \\
Mtx-Glu $_{5}$-Penetratin(desMet) & $0.1(0.1)$ & $>100$ \\
Mtx-GFLG-Arg $_{8}$ & $19.1(3.7)$ & $31.3(9.6)$ \\
Mtx-GFLG-Penetratin(desMet) & $5.5(0.5)$ & $13.9(0.5)$ \\
Mtx-Glu $_{5}-$ GFLG-Arg & $\sim 100$ & $>100$ \\
Mtx-Glu $_{5}$-GFLG-Penetratin(desMet) & $0.4(0.1)$ & $0.3(0.1)$ \\
\hline
\end{tabular}

${ }^{a}$ The cells were incubated with the compound for $3 \mathrm{~h}$, after cultured in serum-containing medium for 3 days. The $\mathrm{IC}_{50}$ values were determined by MTT assay as described in the text. Standard deviation values (sd) are also presented.

In the agreement with the literature [46], free MTX was ineffective against the resistant MDA-MB-231 cells $\left(\mathrm{IC}_{50}>100 \mu \mathrm{M}\right)$ as compared to the MCF-7 cells (Table 2). The cellpenetrating peptides had also no effect on these cells in the applied concentration range $\left(\mathrm{IC}_{50}\right.$ $>100 \mu \mathrm{M})$. Although the cell-penetrating peptide can transport the covalently attached MTX very effectively (see the next section), only the MTX-Penetratin(desMet) had low activity $\left(\mathrm{IC}_{50}=12.9 \mu \mathrm{M}\right)$. Incorporation of the pentapeptide of Glu resulted in a highly cytostatic compound $\left(\mathrm{IC}_{50}=0.1 \mu \mathrm{M}\right)$. In contrast, similar conjugate with octaarginine did not improve the cytostaic effect against the resistant MDA-MB-231 cells $\left(\mathrm{IC}_{50}=100 \mu \mathrm{M}\right.$ for both MTX$\mathrm{Arg}_{8}$ and MTX-Glu $-\mathrm{Arg}_{8}$ ). Incorporation of the GFLG tetrapeptide spacer between the cellpenetrating peptide and MTX increased the activity of both conjugates. The presence of this tetrapeptide did not elevate the activity of $\mathrm{MTX}^{-\mathrm{Glu}_{5}}$ conjugates. Based on the in vitro cytostatic effect on MDA-MB-231 cells the following order could be established among conjugates containing penetratin(desMet): $\mathrm{MTX}-\mathrm{Glu}_{5}$-Penetratin(desMet) $\left(\mathrm{IC}_{50}=0.1 \mu \mathrm{M}\right)>$ MTX-Glu 5 -GFLG-Penetratin(desMet) $\left(\mathrm{IC}_{50}=0.4 \mu \mathrm{M}\right)>$ MTX-GFLG-Penetratin(desMet) $\left(\mathrm{IC}_{50}=5.5 \mu \mathrm{M}\right)>\mathrm{MTX}-$ Penetratin(desMet $)\left(\mathrm{IC}_{50}=12.9 \mu \mathrm{M}\right)$.

\section{Internalisation of the conjugates}

Based on the in vitro cytostatic activity of the conjugates, cellular uptake profile of some conjugates was investigated by flow cytometry. Considering difficulties in measuring the cellular uptake based on the spectroscopic properties of MTX we have prepared conjugates in 
which the drug was replaced by 5(6)-carboxyfluorescein (cf). The cellular uptake profile of these compounds was studied and accepted as an approximation for the uptake of the relevant MTX-Glu 5 -CPP or MTX-CPP conjugates.

First, we were interested in studying the uptake properties of conjugates containing five glutamic acid residues by MTX sensitive and resistant cells. MCF-7 and MDA-MB-231 cells were treated with the solution of cf labelled compounds using in the concentration range of 1 to $10 \mu \mathrm{M}$ at RT for $90 \mathrm{~min}$. After washing and trypsin treatment the fluorescence intensity of the cells was measured by flow cytometry (Figure 2). All conjugates were able to penetrate into the cells and the amount of internalised conjugates was increased by the elevated concentration. Based on the fluorescence intensity of the cells the internalisation of cf labelled octaarginine was higher than that of cf-Penetratin(desMet) on both cell lines. The intracellular amount of octaarginine was significantly increased by the concentration (mean fluorescence of MCF-7 cells: $975(1 \mu \mathrm{M})<8669(5 \mu \mathrm{M})<52928(10 \mu \mathrm{M})$, Figure 2A). The cellularuptake of penetratin(desMet) also showed growing value with the concentrations, but the rise was lower (mean fluorescence of MCF-7 cells: $1728(1 \mu \mathrm{M})<7361(5 \mu \mathrm{M})<12310(10 \mu \mathrm{M})$, Figure 2A). The internalisation of octaarginine was more pronounced on MDA-MB-231 cells while the penetratin had similar cellular uptake on both cell lines.

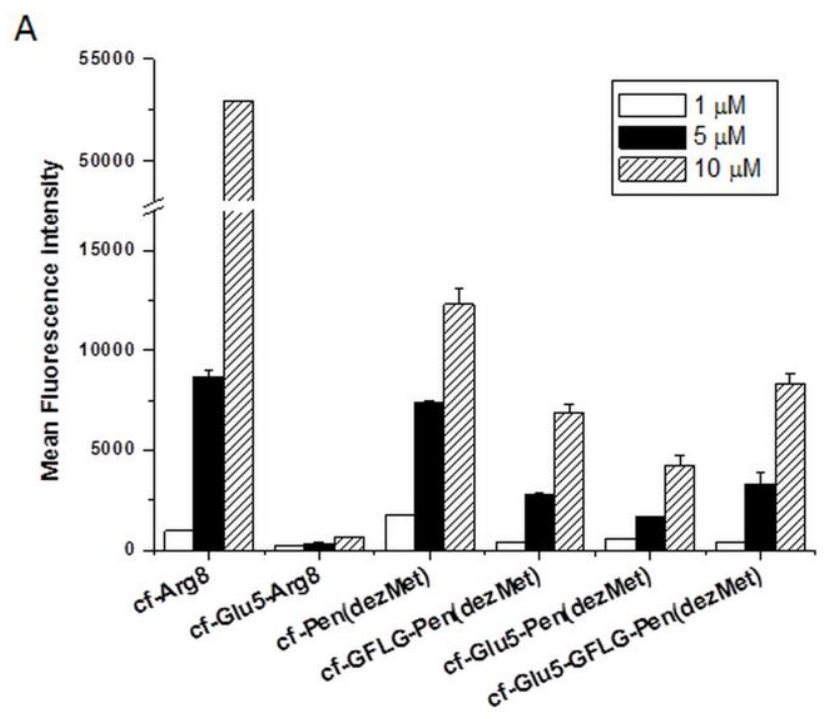




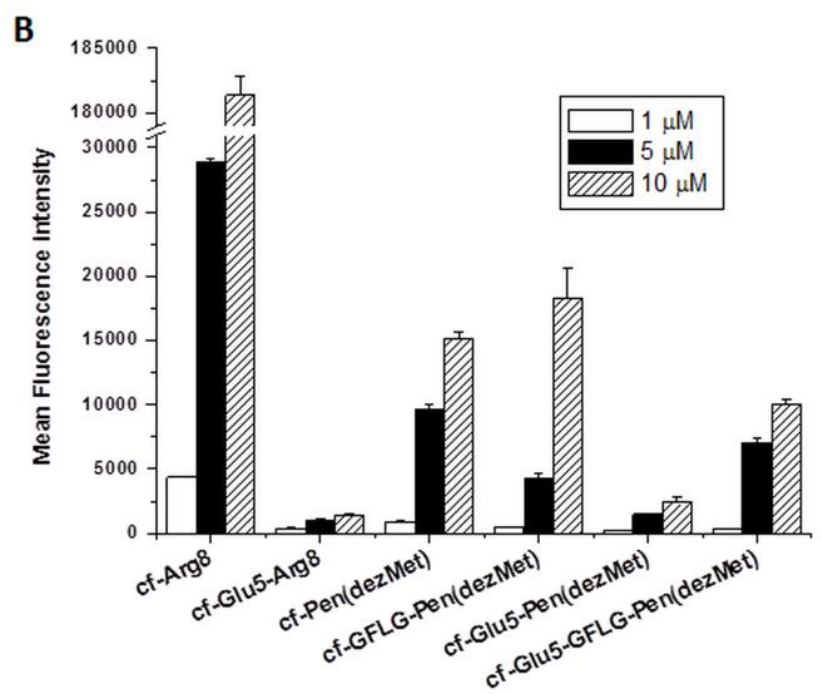

Figure 2 Cellular-uptake profile of fluorescently labelled conjugates by different cells A) MCF-7 and B) MDA-MB-231 cells were treated with the solution of the conjugates (1, 5 and $10 \mu \mathrm{M}$ ) for $90 \mathrm{~min}$. The fluorescence intensity of the cells was determined by flow cytometry after trypsin treatment.

The presence of pentaglutamyl moiety significantly reduced the cellular uptake of the cellpenetrating peptides. This reduction was the highest in case of octaarginine on both cell cultures. The fluorescence intensity decreased below the $10 \%$ of the non-glutamylated form. In case of penetratin(desMet) the reduction was lower and the pentaglutamylated penetratin(desMet) could be internalised more efficiently than the octaarginine derivative. Not only the fluorescence intensity, but also the number of fluorescence positive cells was decreased. At $1 \mu \mathrm{M}$ concentration only a few percent of the cells engulfed the pentaglutamylated conjugates (data is not shown).

We also studied the effect of tetrapeptide spacer on the internalisation of penetratin(desMet) derivatives. Incorporation of GFLG between the pentaglutamyl moiety and the penetratin(desMet) increased significantly the cellular uptake, but it was still lower in comparison with the free penetratin(desMet).

\section{Discussion}

The MTX is an active clinically used antitumor drug. Unfortunately tumor cells may become resistant against it due to the development of several potential processes. Two of these are in relation with the inadequate accumulation of MTX in the cytosol caused by the decreased influx or increased efflux and the lack of polyglutamation. In case of sensitive cells the MTX influx is adequate to achieve the proper intracellular concentration and the drug could inhibit the proliferation (for example MCF-7 cells; Table 2). If this influx is insufficient drug resistance could develop (for example MDA-MB-231 cells; Table 2). The accumulation of MTX in sensitive or resistant cells can be enhanced for example by using delivery vehicle (peptides, polymers, nanoparticles) or in the absence of polyglutamation mechanism by intracellular targeting of polyglutamylated MTX. Among others, two main steps could influence the activity of free and conjugated MTX derivative: internalisation across the cellmembrane, and the interaction with the target enzymes. 
In our systematic study we compared the in vitro antitumor effect of new cell-penetrating conjugates of MTX and MTX-Glu 5 . Two cell-penetrating peptides were applied in these conjugates, octaarginine and penetratin without Met (penetratin(desMet), with or without tetrapeptide spacer (GFLG). From these compounds MTX might be released only after the degradation of peptide and/or the enzymatic cleavage of GFLG spacer. As the GFLG spacer can be cleaved by Cathepsin B lysosomal enzyme both the degradation and the enzyme cleavage can occur in case of vesicular transport, but not in case of direct translocation.

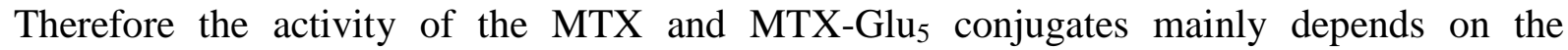
internalisation properties and inhibitory activity of the conjugates.

The in vitro cytostatic effect of the conjugates was measured on resistant and sensitive breast cancer cell lines; MDA-MB-231 and MCF-7 cells, respectively. The MTX was active only on MCF-7 cells and did not show any activity on the resistant cell culture. The effect of cellpenetrating peptides on the cytostatic activity was very divergent. Only the penetratin derivatives exhibited activity. Although the activity of this conjugate was lower on MCF-7 cells compared to the free MTX, it was effective against MDA-MB-231 cells too. The reduction of the efficiency of MTX in the conjugates could be explained by the limited inhibition of the target enzymes by the conjugated forms. Earlier studies reported that conjugation with different carrier molecules decreased the enzyme inhibitory activity of MTX [25,31]. The alteration of the efficacy of octaarginine and penetratin(desMet) conjugates cannot be explained with the different internalisation ability of the cell-penetrating peptides. However, octaarginine efficiently penetrate into both cell lines (Figure 2), it has no in vitro cytostatic activity (Table 2). According to this observation, it was supposed that the internalised octaarginine conjugates cannot inhibit the target intracellular enzymes as much as the penetratin(desMet) ones. For studying if the mechanism of internalisation may cause this difference, enzyme labile spacer was introduced between the MTX and the CPP. The GFLG tetrapeptide spacer applied can be cleaved by cathepsin B enzyme in the lysosomes. Thus if the cells take up the conjugates by any kind of vesicular transport, the cleavage of this spacer may enhance the activity of the compound. While the presence of this spacer slightly increased the effect of penetratin(desMet) conjugate, it is significantly increased the activity of octaarginine conjugate. Based on these findings we suppose that a) the octaarginine conjugate mainly penetrate into the cells by vesicular transport, which is accordance with published data about the internalisation of oligoarginines [47] and/or b) the release of MTX from the conjugate is necessary.

In case of the conjugates of MTX-Glu on MCF-7 and MDA-MB-231 cells. The penetratin(desMet) based conjugate was very active on resistant cells, but was inactive on sensitive cells. The effect of this conjugate was higher than that of the free MTX on sensitive cells. The presence of pentaglutamyl moiety in the conjugates reduces dramatically the internalisation of CPP's on both cell lines. This reduction was more pronounced in case of the octaarginine construct. Our data are in accord with earlier data describing that the positively charged guanidine groups are essential in the internalisation of oligoarginines [48]. The negatively charged glutamic acid residues which could be close to the positively charged guanidine groups can establish electrostatic interaction and thus prevent the binding of cell-penetrating peptide to the cell membrane. This interpretation could be supported with the class of "activatable cell-penetrating peptides" [49]. In these constructs 
poly anionic peptide domains (mainly $\mathrm{Glu}_{\mathrm{n}}$ ) can inhibit the internalisation of poly cationic oligoarginines via electrostatic interaction. Removal of this inhibitory domain results in increased cellular uptake. The results of the cellular-uptake study published [50] showed that the arginines are important in the internalisation of penetratin(desMet), but their possible blocking in our constructs do not diminish fully the uptake. The effect of penetratin(desMet) conjugates on viability was more marked in the case of resistant MDA-MB-231 cells. While penetratin(desMet) can internalise at the similar extent into both cells, the cellular-uptake of pentaglutamylated derivative by resistant cells was smaller. The difference between the in vitro cytostatic activities of the two sets of conjugates may be explained with the altered mechanism of cellular uptake and/or with the altered enzyme sets present in the two cell lines. Based on the fluorescence intensity of the cells only the internalised amount of conjugates was measured, but the mechanism of the penetratin(desMet) translocation needs further investigations, considering that the mechanism of uptake can influence the intracellular distribution of the conjugates (cytosol vs vesicles) and thus the interactions with intracellular target enzymes. The altered mechanism may be responsible for the divergent in vitro cytostatic activity. However, to best of our knowledge there are no data in the literature about the cell-line dependent internalisation mechanism of cell-penetrating peptides. The other possible explanation of differences may be due to the altered enzyme set of different cells, and the differential binding ability of conjugates to these enzymes.

The unwanted interaction of pentaglutamyl moiety with the positively charged cellpenetrating peptides may cause the ineffectiveness of conjugates. Therefore the effect of spacer was also studied. This spacer increases the distance between the positively and negatively charged peptide domains and therefore may inhibit their unwanted interaction. Besides this, the GFLG tetrapeptide used as an enzyme labile spacer may increase the intracellular release of pentaglutamylated-MTX. The presence of GFLG spacer resulted in very effective penetratin conjugates on MCF-7 cells, but had no effect on the activity of MTX-Glu ${ }_{5}$ conjugates on MDA-MB-231 cells. The activity of this conjugate was similar to that of the free MTX. In case of MTX the insertion of the spacer improved the activity of octaarginine conjugate, but the MTX-Glu ${ }_{5}-$ GFLG- Arg $_{8}$ conjugate was fully ineffective. As the cytostatic activity of penetratin(desMet) conjugate was drastically enhanced by the insertion of GFLG spacer on MCF-7 cells, we can suppose that the release of MTX-Glu 5 after cathepsin $\mathrm{B}$ cleavage contributed to the higher effect on the activity. The lack of its influence in octaarginine conjugate may mean that the cellular uptake is very inefficient to produce effective MTX-Glu 5 concentration. To support these, the investigation of Cathepsin B enzyme cleavage of conjugates is planned. Based on the results and the inhibitory activity of conjugates and fragments on DHFR enzyme activity the smallest active compounds will be identified. Thus, at the moment it is early to propose even a hypothesis about the mechanism of action and structure-activity relationship. However, we are convinced that the observation presented in this paper is novel and important to communicate.

Our results presented here demonstrate that the delivery of polyglutamylated MTX into tumor cells could result in pronounced improvement on the cytostatic effect on tumor cells in vitro. These data also highlight that the choice of cell-penetrating peptide and the design of the conjugate are important, since the selected CPP may have marked influence on the activity. Taking into consideration the possible limitations of CPP in in vivo measurements for 
example degradability, toxicity, further studies are planned to prove the potency of conjugate(s) presented as lead molecules in vivo.

\section{Conclusions}

The resistance of tumor cells against antitumor drugs is a growing problem in the cancer therapy. Therefore new drugs and/or the modification of existing ones circumventing the drug resistance is an intensively researched area. MTX is an effective antitumor compound, but the evolved drug resistance often hampers its use. In many cases the inefficient internalisation or polyglutamation could be responsible for the drug resistance. In this paper we described a new set of conjugates of MTX and its pentaglutamylated derivative (MTX-Glu 5 ) combined with cell-penetrating peptide - octaarginine and penetratin(desMet). Although both cell-penetrating peptides were successfully used to deliver antitumor drug into cells, as reported in the literature, our results indicate that the penetratin(desMet) conjugates were more effective than the respective octaarginine conjugates under in vitro conditions. The delivery of MTX into cells was effective against MTX resistant MDA-MB-231 cells. The penetratin(desMet) conjugates containing MTX-Glu ${ }_{5}$ had the same activity on resistant cells than the free MTX on sensitive cells. The MTX-Glu ${ }_{5}$-Penetartin(desMet) and MTX-Glu ${ }_{5}$-GFLGPenetratin(desMet) conjugates were very active against resistant tumor cells, and the MTXGlu 5 -GFLG-Penetratin(desMet) had also increased efficacy against sensitive cells. Our results suggest that the delivery of polyglutamylated MTX by cell-penetrating peptide may reopen the way of the effective treatment of tumors. The activity of conjugates also highlights that although the internalisation of cell-penetrating peptide is very similar, the small differences may cause significantly altered activity.

\section{Acknowledgements:}

Financial support of the Hungarian Scientific Research Fund (OTKA, grant number K 104385, PD 103963 and PD 104012) is greatly acknowledged. Gitta Schlosser acknowledges the János Bolyai research fellowship of the Hungarian Academy of Sciences (MTA).

All authors declare no conflict of interest.

\section{Author contributions}

Designed the experiments: ZB, ISz, GS, FH

Performed the experiments: ZB, ISz, GS, EO

Analysed and interpreted the data: ZB, ISz, GS, EO, FH

Wrote the paper: ZB, ISz, GS, EO, FH

Revised critically the paper: all authors

All authors read and approved the final version of the manuscript. 


\section{References}

[1] Walling, J. (2006) From methotrexate to pemetrexed and beyond. A review of the pharmacodynamic and clinical properties of antifolates. Invest New Drugs 24, 37-77.

[2] Chen, C., Ke, J., Zhou, X. E., Yi, W., Brunzelle, J. S., Li, J., Yong, E. L., Xu, H. E., and Melcher, K. (2013) Structural basis for molecular recognition of folic acid by folate receptors. Nature 500, 486-489.

[3] Schirch, V., and Strong, W. B. (1989). Interaction of folylpolyglutamates with enzymes in onecarbon metabolism. Arch. Biochem. Biophys. 269, 371-380.

[4] Allegra, C. J., Chabner, B. A., Drake, J. C., Lutz, R., Rodbard, D., and Jolivet, J. (1985) Enhanced inhibition of thymidylate synthase by methotrexate polyglutamates. J. Biol.Chem. 260, 9720-9726.

[5] Chabner, B. A., Allegra, C. J., Curt, G. A., Clendeninn, N. J., Baram, J., Koizumi, S., Drake, J. C., and Jolivet, J. (1985) Polyglutamation of methotrexate. Is methotrexate a prodrug? J. Clin. Invest. 76, 907-912.

[6] Schoo, M. M., Pristupa, Z. B., Vickers, P. J., and Scrimgeour, K. G. (1985) Folate analogues as substrates of mammalian folylpolyglutamate synthetase. Cancer Res. 45, 30343041 .

[7] Zeng, H., Chen, Z. S., Belinsky, M. G., Rea, P. A., and Kruh, G. D. (2001). Transport of methotrexate (MTX) and folates by multidrug resistance protein (MRP) 3 and MRP1: Effect of polyglutamylation on MTX transport. Cancer Res. 61, 7225-7232.

[8] Jolivet, J., and Chabner, B. A. (1983) Intracellular pharmacokinetics of methotrexate polyglutamates in human breast cancer cells. Selective retention and less dissociable binding of 4 $\mathrm{NH}_{2}-10-\mathrm{CH}_{3}$-pteroylglutamate 4 and $4-\mathrm{NH}_{2}-10-\mathrm{CH}_{3}$-pteroylglutamate ${ }_{5}$ to dihydrofolate reductase. $J$. Clin. Invest. 72, 773-778.

[9] Wang, T. T., Chandler, C. J., and Halsted, C. H. (1986) Intracellular pteroylpolyglutamate hydrolase from human jejunal mucosa. Isolation and characterization. J Biol Chem, 261, 13551-13555.

[10] Schneider, E., and Ryan, T. J. (2006) Gamma-glutamyl hydrolase and drug resistance. Clinica Chimica Acta 374, 25-32.

[11] Sirotnak, F. M., Kurita, S., and Hutchison, D. J. (1968) On the nature of a transport alteration determining resistance to amethopterin in the L1210 leukemia. Cancer Res. 28, 75-80.

[12] Assaraf, Y. G. (2006) The role of multidrug resistance efflux transporters in antifolate resistance and folate homeostasis. Drug Resist. Updat. 9, 227-246.

[13] McCloskey, D. E., McGuire, J. J., Russell, C. A., Rowan, B. G., Bertino, J. R., Pizzorno, G., and Mini, E. (1991) Decreased folylpolyglutamate synthetase activity as a mechanism of resistance in CCRF-CEM human leukemia sublines. J. Biol. Chem. 266, 6181-6187. 
[14] Li, W. W., Lin, J. T., Tong, W. P., Trippett, T. M., Brennan, M. F., and Bertino, J. R. (1992) Mechanisms of natural resistance to antifolates in human soft tissue sarcomas. Cancer Res 52, 1434-1438.

[15] Whitehead, V. M., Vuchich, M. J., Lauer, S. J., Mahoney, D., Carroll, A. J., Shuster, J. J., Esseltine, D. W., Payment, C., Look, A. T., Akabutu, J., Bowen, T., Taylor, L. D., Camitta, B., and Pullen, D. J. (1992) Accumulation of high levels of methotrexate polyglutamates in lymphoblasts from children with hyperdiploid ( $>50$ chromosomes) B lineage acute lymphoblastic leukemia: A Pediatric Oncology Group Study. Blood 80, 1316-1323.

[16] Frankel, A. D., and Pabo, C. O. (1988) Cellular uptake of the Tat protein from human immunodeficiency virus. Cell 55, 1189-1193.

[17] Green, M., and Loewenstein, P. M. (1988) Autonomousfunctional domains of chemically synthesized humanism immunodeficiency virus Tat trans-activator protein. Cell 55, 1179-1186.

[18] Joliot, A., Pernelle, C., Deagostini-Bazin, H., and Prochiantz, A. (1991) Antennapedia homeobox peptide regulates neural morphogenesis. Proc. Natl. Acad. Sci. U.S.A. 88, 1864-1868.

[19] Hudecz, F., Bánóczi, Z., and Csík, G. (2005) Medium-sized peptides as built in carriers for biologically active compounds. Med. Res. Rev. 25, 679-736.

[20] Miklán, Zs., Orbán, E., Bánóczi, Z., and Hudecz, F. (2011) New pemetrexed-peptide conjugates: synthesis, characterization and cytostatic effect on non-small cell lung carcinoma (NCI-H358) and human leukemia (HL-60) cells. J. Peptide Science, 17, 805-811.

[21] Burger, A. M., Hartung, G., Stehle, G., Sinn, H., and Fiebig, H. H. (2001) Pre-clinical evaluation of a methotrexate-albumin conjugate (MTX-HSA) in human tumor xenografts in vivo. Int. J. Cancer. 92, 718-724.

[22] Mezö, G., Láng, O., Jakab, A., Bai, K. B., Szabó, I., Schlosser, G., Láng, J., Köhidai, L., and Hudecz, F. (2006) Synthesis of oligotuftsin-based branched oligopeptide conjugates for chemotactic drug targeting. J. Pept. Sci. 12, 328-336.

[23] Nagy, A., Szőke, B., and Schally, A. V. (1993) Selective coupling of methotrexate to peptide hormone carriers through a gamma-carboxamide linkage of its glutamic acid moiety: benzotriazol-1-yloxytris(dimethylamino)phosphonium hexafluorophosphate activation in salt coupling. Proc. Natl. Acad. Sci. USA 90, 6373-6376.

[24] Brunetti, J., Falciani, C., Lelli, B., Minervini, A., Ravenni, N., Depau, L., Siena, G., Tenori, E., Menichetti, S., Pini, A., Carini, M., and Bracci, L. (2015) Neurotensin branched peptide as a tumor-targeting agent for human bladder cancer. BioMed Res. Int. 2015, Article ID 173507.

[25] Lindgren, M., Rosenthal-Aizman, K., Saar, K., Eiriksdottir, E., Jiang, Y., Sassian, M., Ostlund, P., Hallbrink, M., and Langel, U. (2006) Overcoming methotrexate resistance in breast cancer tumour cells by the use of a new cell-penetrating peptide. Biochem. Pharmacol. $71,416-425$. 
[26] Hudecz, F., Clegg, J. A., Kajtár, J., Embleton, M. J., Pimm, M. V., Szekerke, M., and Baldwin, R. W. (1993) Influence of carrier on biodistribution and in vitro cytotoxicity of methotrexate-branched polypeptide conjugates. Bioconjugate Chem. 4, 25-33.

[27] Kaminskas, L. M., McLeod, V. M., Ascher, D. B., Ryan, G. M., Jones, S., Haynes, J. M., Trevaskis, N. L., Chan, L. J., Sloan, E. K., Finnin, B. A., Williamson, M., Velkov, T., Williams, E. D., Kelly, B. D., Owen, D. J., and Porter, C. J. (2015) Methotrexate-conjugated PEGylated dendrimers show differential patterns of deposition and activity in tumor-burdened lymph nodes after intravenous and subcutaneous administration in rats. Mol. Pharmaceutics $12,432-443$.

[28] Myc, A., Douce, T. B., Ahuja, N., Kotlyar, A., Kukowska-Latallo, J., Thomas, T. P., and Baker J. R. Jr, (2008) Preclinical antitumor efficacy evaluation of dendrimer-based methotrexate conjugates. Anticancer Drugs. 19, 143-149.

[29] Chau, Y., Dang, N. M., Tan, F. E., and Langer, R. (2006) Investigation of targeting mechanism of new dextran-peptide-methotrexate conjugates using biodistribution study in matrix-metalloproteinase-overexpressing tumor xenograft model. J. Pharm. Sci. 95, 542-551.

[30] Abraham, A., Nair, M. G., Kislik, R. L., Gaumont, Y., and Galivan, J. (1990) Folate analogues. 33. Synthesis of folate and antifolate poly-gamma-glutamates by [(9fluorenylmethoxy)oxy]carbonyl chemistry and biological evaluation of certain methotrexate polyglutamate polylysine conjugates as inhibitors of the growth of H35 hepatoma cells. $J$. Med. Chem. 33, 711-717.

[31] Lächelt, U., Wittmann, V., Müller, K., Edinger, D., Kos, P., Höhn, M., and Wagner, E. (2014) Synthetic polyglutamylation of dual-functional MTX ligands for enhanced combined cytotoxicity of poly(I:C) nanoplexes. Mol. Pharm. 11, 2631-2639.

[32] Bánóczi, Z., Gorka-Kereskényi, A., Reményi, J., Orbán, E., Hazai, L., Tőkési, N., Oláh, J., Ovádi, J., Béni, Z., Háda, V., Szántay, Cs. Jr., Hudecz, F., Kalaus, G., and Szántay, Cs. (2010) Synthesis and in vitro antitumor effect of vinblastine derivative-oligoarginine conjugates. Bioconjugate Chem., 21, 1948-1955.

[33] Bánóczi, Z., Peregi, B., Orbán, E., Szabó, R., and Hudecz, F. (2007) Synthesis of Daunomycin - oligoarginine conjugates and their effect on Human leukemia cells (HL-60). Arkivoc, 2008, Part (iii), 140-153.

[34] Bánóczi, Z., Tantos, Á., Farkas, A., Tompa, P., Friedrich, P., and Hudecz, F. (2007) Synthesis of cell-penetrating conjugates of calpain activator peptides. Bioconjugate Chem. 18, 130-137.

[35] Bánóczi, Z., Alexa, A., Farkas, A., Friedrich, P., and Hudecz, F. (2008) Novel cellpenetrating calpain substrate. Bioconjugate Chem. 19, 1375-1381. 
[36] Kaiser, E., Colescott, R. L., Bossinger, C. D., and Cook, P. I. (1970) Color test for detection of free terminal amino groups in the solid-phase synthesis of peptides. Anal. Biochem. 34, 595-598.

[37] Soule, H. D., Vazguez, J., Long, A., Albert, S., and Brennan, M. (1973) A human cell line from a pleural effusion derived from a breast carcinoma. J. Natl. Cancer. Inst. 51, 14091416.

[38] Cailleau, R., Young, R., Olivé, M., and Reeves, W. J. Jr., (1974) Breast tumor cell lines from pleural effusions. J. Natl. Cancer Inst. 53, 661-674.

[39] Slater, T. F., Sawyer, B., and Sträuli, U. (1963) Studies on succinate-tetrazolium reductase systems. III. Points of coupling of four different tetrazolium salts. Biochim. Biophys. Acta. 77, 383-93.

[40] Mosmann, T. (1983) Rapid colorimetric assay for cellular growth and survival: application to proliferation and cytotoxicity assays. J. Immunol. Methods 65, 55-63.

[41] Ziegler, A. (2008) Thermodynamic studies and binding mechanisms of cell-penetrating peptides with lipids and glycosaminoglycans. Adv. Drug Deliv. Rev. 60, 580-597.

[42] Derossi, D., Calvet, S., Trembleau, A., Brunissen, A., Chassaing, G., and Prochiantz, A. (1996) Cell internalization of the third helix of the Antennapedia homeodomain is receptorindependent. J. Biol. Chem. 271, 18188-18193

[43] Gonçalves, E., Kitas, E., and Seelig, J. (2005) Binding of oligoarginine to membrane lipids and heparan sulfate: structural and thermodynamic characterization of a cell-penetrating peptide. Biochemistry 44, 2692-2702.

[44] Letoha, T., Gaál, S., Somlai, C., Czajlik, A., Perczel, A., and Penke, B. (2003) Membrane translocation of penetratin and its derivatives in different cell lines. $J \mathrm{Mol}$ Recognit. 16, 272-279.

[45] Subik, K., Lee, J. F., Baxter, L., Strzepek, T., Costello, D., Crowley, P., Xing, L., Hung, M. C., Bonfiglio, T., Hicks, D. G., and Tang P. (2010) The Expression Patterns of ER, PR, HER2, CK5/6, EGFR, Ki-67 and AR by Immunohistochemical Analysis in Breast Cancer Cell Lines. Breast Cancer (Auckl) 4, 35-41.

[46] Moscow, J. A., Connolly, T., Myers, T. G., Cheng, C. C., Paull, K., and Cowan,K. H. (1997) Reduced folate carrier gene (RFC1) expression and anti-folate resistance in transfected and non-selected cell lines. Int. J. Cancer 72, 184-190.

[47] Nakase, I., Niwa, M., Takeuchi, T., Sonomura, K., Kawabata, N., Koike, Y., Takehashi, M., Tanaka, S., Ueda, K., Simpson, J. C., Jones, A. T., Sugiura, Y., and Futaki, S. (2004) Cellular uptake of arginine-rich peptides: roles for macropinocytosis and actin rearrangement. Mol. Ther. 10, 1011-1022. 
[48] Mitchell, D. J., Kim, D. T., Steinman, L., Fathman, C. G., and Rothbard, J. B. (2000) Polyarginine enters cells more efficiently than other polycationic homopolymers. J Pept Res. 56, 318-25.

[49] Jiang, T., Olson, E. S., Nguyen, Q. T., Roy, M., Jennings, P. A., and Tsien, R. Y. (2004) Tumor imaging by means of proteolytic activation of cell-penetrating peptides. Proc. Natl. Acad. Sci. U S A 101, 17867-17872.

[50] Thorén, P. E., Persson, D., Isakson, P., Goksör, M., Onfelt, A., and Nordén, B. (2003) Uptake of analogs of penetratin, Tat(48-60) and oligoarginine in live cells. Biochem Biophys Res Commun. 307, 100-107. 